\title{
Antimicrobial Efficacy of Octenidine Hydrochloride, Green Tea, Sodium Hypochlorite and Chlorhexidine Gluconate as Retreatment Endodontic Irrigant Against E. faecalis, Candida \& Mixed Culture - In-Vitro Study
}

\author{
Reetika S. Khandelwal ${ }^{1}$, Shivkumar P. Mantri² ${ }^{2}$ Bonny Paul ${ }^{3}$, Kavita A. Dube ${ }^{4}$, Gargi Mishra ${ }^{5}$, Vrinda R. Dhirawani ${ }^{6}$
}

1, 2, 3, 4, 5, 6 Department of Conservative Dentistry \& Endodontics,

Hitkarini Dental College, Jabalpur, Madhya Pradesh, India.

\section{ABSTRACT}

\section{BACKGROUND}

Sodium hypochlorite \& chlorhexidine are usually employed as endodontic irrigants due to their antimicrobial properties, however, their cytotoxicity \& allergenicity issues demand an equally effective but safer irrigant. The purpose of the study was to compare the antimicrobial efficacy of octenidine hydrochloride (OCT), green tea, sodium hypochlorite and chlorhexidine (CHX) at various concentrations against $E$. faecalis, C. albicans and its mixture.

\section{METHODS}

The study was conducted in Hitkarini Dental College, Jabalpur. Various concentrations of irrigants were prepared. Muller Hinton agar media plates were swabbed with the culture broth of $E$ faecalis ATCC 29212, Candida albicans ATCC 10231 or a mixture of these. Five Whatman paper disks $(6 \mathrm{~mm})$, each loaded with experimental concentration of the irrigant, were placed at equal distance on to the plate. The plates were incubated at $37^{\circ} \mathrm{C}$ for 48 hours. This was done in 6 replicates. The plates were evaluated for clear zone of inhibition measured in $\mathrm{mm}$.

\section{RESULTS}

The diameter readings were analysed using Kruskal Wallis and Mann Whitney U tests. There was a significant difference between the groups against Enterococcus faecalis; candida, \& mixed culture $(\mathrm{P}<0.01)$.

\section{CONCLUSIONS}

$5 \%$ Sodium hypochlorite is better than all others whereas $2 \%$ CHX is better than OCT \& Green tea. $0.1 \%$ OCT is better than $3 \%$ Green tea. OCT can be used as a contributory irrigant along with $\mathrm{NaOCl}$ to achieve antimicrobial advantage.

\section{KEY WORDS}

Antimicrobial Efficacy, Candida Albicans, Chlorhexidine Gluconate, E Faecalis, Green Tea, Octenidine Hydrochloride, Sodium Hypochlorite
Corresponding Author: Dr. Shivkumar P. Mantri, BDS, MDS, MBA, Professor \& Head, Department of Conservative Dentistry \& Endodontics, Hitkarini Dental College, Dumna Airport Road, Jabalpur, Madhya Pradesh India.

E-mail: shivmantri24@gmail.com

DOI: $10.14260 /$ jemds/2021/538

How to Cite This Article:

Khandelwal RS, Mantri SP, Paul B, et al. Antimicrobial efficacy of octenidine hydrochloride, green tea, sodium hypochlorite and chlorhexidine gluconate as retreatment endodontic irrigant against E faecalis, candida \& mixed culture - invitro study. J Evolution Med Dent Sci 2021;10(32):2629-2633, $10.14260 /$ jemds/2021/538

Submission 21-04-2021, Peer Review 05-07-2021, Acceptance 11-07-2021, Published 09-08-2021.

Copyright (C) 2021 Reetika S. Khandelwal et al. This is an open access article distributed under Creative Commons Attribution License [Attribution 4.0 International (CC BY 4.0)] 


\section{BACKGROUND}

Decontamination and debridement play an important role in the success of endodontic treatment. Residual microorganisms are found in pulpal spaces and dentin tubules, and many of them cause recurrent intraradicular infection after root canal treatment. E. faecalis is frequently observed in a high percentage of root canal failures. The frequency of $E$. faecalis association in primary endodontic infection ranges from $4-40 \%$ and $24-77 \%$ in persistent infections. ${ }^{1} \mathrm{C}$. albicans has been found to be present in the oral cavity in 30 to $45 \%$ of healthy adults and $95 \%$ of patients infected with the human immunodeficiency virus. ${ }^{1}$ Infections of the primary root canal have been known to contain fungi occasionally. They appear to be more common in the root canals of obturated teeth that have failed treatment. ${ }^{2}$

Sodium hypochlorite $(\mathrm{NaOCl})$ is the gold standard for the irrigation of root canal space because of the clinical efficacy \& extensive research in endodontic therapy. ${ }^{2}$ Due to toxicity concerns, it was suggested that $5.25 \% \mathrm{NaOCl}$ be diluted to lower concentrations. It has a foul odour and taste, bleaches clothing, has corrosive potential and when extruded into the periapical tissues, it is cytotoxic. Chlorhexidine gluconate (CHX) has been advocated as an endodontic irrigant due to its antibacterial effects, and lower cytotoxicity but greater substantivity than $\mathrm{NaOCl}$ and efficient clinical accomplishment. ${ }^{3}$ Since CHX is highly cytotoxic in-vitro, caution should be exercised while using it in oral procedures. ${ }^{4}$ It has also been linked to allergic reactions. As a result, a similarly efficient yet safer irrigant is desired. ${ }^{5}$

Octenidine hydrochloride (OCT), a bispyridine derivative, has been recommended as an endodontic irrigant due to its antimicrobial effects and lower cytotoxicity. ${ }^{5}$ It tends to be more effective than chlorhexidine for bacterial antiadhesion activity that lasts longer. It is stable under different physical and chemical conditions and not prone to hydrolysis. The mode of action is bactericidal / fungicidal by interfering with cell walls and membranes. ${ }^{6}$ Green tea polyphenols are herbal derivatives from Camellia sinensis leaves. GTPs have antioxidant, anti-inflammatory, and antimicrobial properties. $^{7}$ Despite extensive literature on the efficacy of these irrigants in primary root canal treatment, there are very few studies of antimicrobial efficacy in different concentrations of these chemicals against E faecalis, Candida albicans and mixed culture.

Hence this study was undertaken to compare the efficacy of various concentrations of irrigant. Purpose of the present study was to evaluate and compare the antibacterial and antifungal efficacy of octenidine hydrochloride, green tea, sodium hypochlorite and chlorhexidine gluconate at various concentrations against $E$. faecalis, $C$. albicans and its mixture.

\section{METHODS}

This in-vitro laboratory study was conducted at Hitkarini dental College, Jabalpur, Madhya Pradesh, India. It spanned for over a period of six months including the procurement of material and conducting the experiment.
Materials were procured and irrigating solutions were prepared as follows -

Octenidine hydrochloride (Dishman Pharmaceuticals and Chemical Ltd Ahmedabad, India), powder was dissolved in methanol to obtain $0.10 \%, 0.05 \% 0.025 \%$ concentrations. Green tea (Vista Nutrition, Bangalore, India) was extracted with ethanol for 24 hours. The extract was dried to get the powdered form. $3 \%, 2.5 \% 2 \%$ were prepared by dissolving it in ethanol.

Chlorhexidine gluconate (Neelkanth - Safe Plus, Jodhpur, India) $2 \%$ was used directly from the bottle. $1 \%$ \& $0.20 \%$ were prepared by diluting $2 \%$ CHX with distilled water. Sodium hypochlorite (Vishal Dentocare Pvt Ltd, Ahmedabad, India), $5 \%$ was used directly from the bottle. $2.5 \%$ \& $0.5 \%$ were prepared by diluting with distilled water. Sterile saline solution 0.9 \% W / V (Aculife Healthcare Pvt Ltd, Vasna, India) was used as control.

Fifteen $\mathrm{ml}$ of hot $\left(50^{\circ}\right.$ to $\left.60^{\circ} \mathrm{C}\right)$, Muller Hinton agar media (HIMEDIA), was poured on the autoclaved culture plates of $100 \mathrm{~mm}$ diameter and was allowed to solidify under laminar air flow. Once the media was solidified, the plates were swabbed with the 6 - 8 hour old culture broth of $E$ faecalis ATCC 29212, Candida albicans ATCC 10231 or a mixture of these. The turbidity of the broth was set to McFarland 0.5 before swabbing. The culture broth was swabbed three times on to the plate, by rotating the plate to $60^{\circ}$ after each swabbing, and allowed to dry. Five Whatman paper disks (6 $\mathrm{mm}$ ), each loaded with the experimental concentration of irrigant, were placed at equal distance on to the plate. The plate was covered with the lid and incubated at $37^{\circ} \mathrm{C}$ for 48 hours.

This was done in 6 replicates. After this, the plates were evaluated for clear zone of inhibition. The diameter of the zone was measured in mm using zone measurement scale.

\section{Statistical Analysis}

Data was entered in Microsoft excel 2013 for Windows. Mean, standard deviation (SD), median, minimum, and maximum values of zone of inhibitions against E. faecalis, candida and mixed culture in different concentrations in different groups were calculated.

Shapiro - Wilk test showed that zone of inhibition values in different groups did not follow normal distribution hence nonparametric test namely, Kruskal Wallis test was used for comparison between experimental groups. When Kruskal Wallis test showed significant difference, Mann Whitney U test was applied for pairwise comparison of groups (comparison of two groups). $\mathrm{P}<0.05$ was considered statistically significant.

\section{RESULTS}

All the experimental irrigants exhibited antibacterial and antifungal properties except saline. Kruskal Wallis test showed significant difference between the groups (Table 1) (Figure 1). Mann Whitney U test for comparison showed that, in low concentrations, $\mathrm{CHX}$ was significantly $(\mathrm{P}<0.01)$ better than all other irrigants against all microbes used in the experiment. 


\begin{tabular}{|c|c|c|c|c|c|c|c|c|c|c|}
\hline \multirow{2}{*}{\multicolumn{2}{|c|}{ Groups }} & \multicolumn{3}{|c|}{ Low } & \multicolumn{3}{|c|}{ Medium } & \multicolumn{3}{|c|}{ High } \\
\hline & & E faecalis & Candida albicans & Mixed & E faecalis & Candida albicans & Mixed & E. faecalis & Candida albicans & Mixed \\
\hline \multirow{3}{*}{ OCT } & Mean \pm SD & $8.18 \pm 0.08$ & $8.10 \pm 0.09$ & $7.30 \pm 0.46$ & $8.35 \pm 0.19$ & $12.20 \pm 0.13$ & $10.25 \pm 0.14$ & $13.12 \pm 0.33$ & $13.10 \pm 0.31$ & $11.13 \pm 0.20$ \\
\hline & Median & 8.20 & 8.10 & 7.15 & 8.35 & 12.15 & 10.20 & 13.20 & 13.15 & 11.05 \\
\hline & Min - Max & $8.10-8.30$ & $8.00-8.20$ & $7.00-8.20$ & $8.10-8.60$ & $12.10-12.40$ & $10.10-10.50$ & $12.50-13.50$ & $12.60-13.40$ & $11.00-11.50$ \\
\hline \multirow{3}{*}{ Green tea } & Mean \pm SD & $0.00 \pm 0.00$ & $0.00 \pm 0.00$ & $0.00 \pm 0.00$ & $7.10 \pm 0.06$ & $8.17 \pm 0.08$ & $0.00 \pm 0.00$ & $7.90 \pm 0.40$ & $12.90 \pm 0.51$ & $8.35 \pm 0.19$ \\
\hline & Median & 0.00 & 0.00 & 0.00 & 7.10 & 8.15 & 0.00 & 8.05 & 13.15 & 8.35 \\
\hline & Min - Max & $0.00-0.00$ & $0.00-0.00$ & $0.00-0.00$ & $7.00-7.20$ & $8.10-8.30$ & $0.00-0.00$ & $7.10-8.10$ & $12.20-13.40$ & $8.10-8.60$ \\
\hline \multirow{3}{*}{$\mathrm{NaOCl}$} & Mean \pm SD & $0.00 \pm 0.00$ & $0.00 \pm 0.00$ & $0.00 \pm 0.00$ & $13.83 \pm 0.41$ & $14.58 \pm 0.49$ & $14.10 \pm 0.49$ & $20.15 \pm 0.08$ & $16.38 \pm 0.25$ & $15.13 \pm 0.12$ \\
\hline & Median & 0.00 & 0.00 & 0.00 & 13.75 & 14.75 & 14.30 & 20.10 & 16.35 & 15.15 \\
\hline & Min - Max & $0.00-0.00$ & $0.00-0.00$ & $0.00-0.00$ & $13.50-14.50$ & $14.00-15.00$ & $13.50-14.50$ & $20.10-20.30$ & $16.10-16.80$ & $15.00-15.30$ \\
\hline \multirow{3}{*}{ CHX } & Mean \pm SD & $13.92 \pm 0.55$ & $10.63 \pm 0.55$ & $8.28 \pm 0.26$ & $15.25 \pm 0.08$ & $12.90 \pm 0.46$ & $12.28 \pm 0.21$ & $16.30 \pm 0.15$ & $14.20 \pm 0.54$ & $14.27 \pm 0.18$ \\
\hline & Median & 14.05 & 10.65 & 8.30 & 15.20 & 12.70 & 12.20 & 16.30 & 14.15 & 14.20 \\
\hline & Min - Max & $13.20-14.50$ & $10.10-11.20$ & $7.90-8.60$ & $15.20-15.40$ & $12.60-13.80$ & $12.10-12.60$ & $16.10-16.50$ & $13.40-15.10$ & $14.10-14.60$ \\
\hline \multirow{3}{*}{ Saline } & Mean \pm SD & $0.00 \pm 0.00$ & $0.00 \pm 0.00$ & $0.00 \pm 0.00$ & $0.00 \pm 0.00$ & $0.00 \pm 0.00$ & $0.00 \pm 0.00$ & $0.00 \pm 0.00$ & $0.00 \pm 0.00$ & $0.00 \pm 0.00$ \\
\hline & Median & 0.00 & 0.00 & 0.00 & 0.00 & 0.00 & 0.00 & 0.00 & 0.00 & 0.00 \\
\hline & Min - Max & $0.00-0.00$ & $0.00-0.00$ & $0.00-0.00$ & $0.00-0.00$ & $0.00-0.00$ & $0.00-0.00$ & $0.00-0.00$ & $0.00-0.00$ & $0.00-0.00$ \\
\hline \multicolumn{2}{|c|}{ Kruskal Wallis Test } & & & & \multicolumn{3}{|c|}{$\mathrm{p}=0.000^{*}$} & \multirow{2}{*}{\multicolumn{3}{|c|}{$\begin{array}{c}\mathrm{P}=0.002 * \\
\text { Candida } \\
\text { OCT \& CHX } \mathrm{P}=0.004^{*} \\
\text { OCT \& Green tea } \mathrm{P}=0.589\end{array}$}} \\
\hline \multicolumn{2}{|c|}{ Mann Whitney U test } & \multicolumn{3}{|c|}{$\begin{array}{c}\mathrm{P}=0.002^{*} \\
\mathrm{P}=1.000 \\
\text { Green tea \& NaOCl, } \\
\text { Green tea \& Saline, } \\
\text { NaOCl \& Saline }\end{array}$} & \multicolumn{3}{|c|}{$\begin{array}{l}P=0.002 * \\
\text { Mixed culture } \\
\text { tea \& Saline } \mathrm{P}=1.000\end{array}$} & & & \\
\hline & & le 1. Co & parison of Zone 0 & hibitio & tween D & ent Groups in & $\overline{\text { Mediun }}$ & High Cc & rations & \\
\hline
\end{tabular}

\section{Comparison of zone of inhibition against E faecalis, Candida \& Mixed culture between different groups in low, medium and high concentrations.}

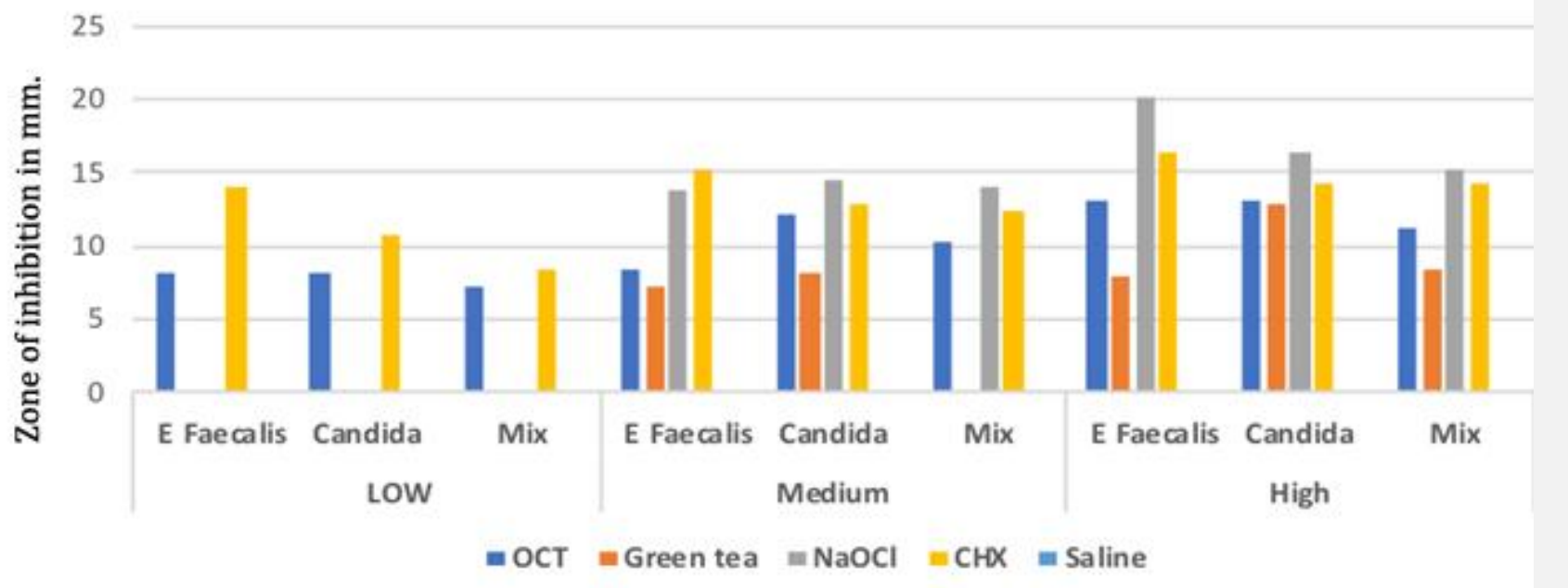

Concentration of irrigants against $\mathrm{E}$ faecalis, Candid and mixed culture.

Figure 1. Zone of Inhibition against E Faecalis, Candida \& Mixed Culture Observed in Low, Medium, and High Concentrations of Different Irrigants

Ranking is: $0.2 \% \operatorname{CHX}(\mathrm{P}<0.01)>0.025 \%$ OCT $(\mathrm{P}<0.01)$ $>0.5 \% \mathrm{NaOCl}=2 \%$ Green tea $=$ Control $(\mathrm{P}>0.05)$. In medium concentration, CHX was significantly better $(\mathrm{P}<0.01)$ than all other irrigants against $E$. faecalis and candida. Ranking is: $1 \% \operatorname{CHX}(\mathrm{P}<0.01)>2.5 \% \mathrm{NaOCl}(\mathrm{P}<0.01)>$ $0.05 \%$ OCT $>2.5 \%$ Green tea $>$ Control. However, in mixed culture, $\mathrm{NaOCl}$ was significantly better $(\mathrm{P}<0.01)$ than all other irrigants. Ranking is: $2.5 \% \mathrm{NaOCl}(\mathrm{P}<0.01)>1 \% \mathrm{CHX}$ $(\mathrm{P}<0.01)>0.05 \%$ OCT $(\mathrm{P}<0.01)>2.5 \%$ Green tea $=$ control against mixed culture. ( $\mathrm{P}>0.05)$.

In high concentrations, $\mathrm{NaOCl}$ was significantly better $(\mathrm{P}$ $<0.01)$ than all other irrigants. Ranking against E. faecalis \& mixed culture is: $5 \% \mathrm{NaOCl}(\mathrm{P}<0.01)>2 \% \mathrm{CHX}(\mathrm{P}<0.01)>$ $0.1 \%$ OCT $(\mathrm{P}<0.01)>3 \%$ Green tea $>$ Control $(\mathrm{P}<0.01)$. However, against candida, there was no significant difference between OCT and Green tea $(\mathrm{P}>0.05)$. Against candida, ranking is: $5 \% \mathrm{NaOCl}(\mathrm{P}<0.01)>2 \% \mathrm{CHX}(\mathrm{P}<0.01)>0.1 \%$ OCT $(\mathrm{P}>0.05)=3 \%$ Green tea $>$ control $(\mathrm{P}<0.01)$.

\section{DISCUSSION}

The efficacy of endodontic irrigant is directly proportional to the concentration and the volume. ${ }^{4}$ The antimicrobial activity of the irrigating solution should be quickly exerted against resistant microorganisms present in root canal and dentinal tubules. ${ }^{5}$ In the present study, $\mathrm{NaOCl}$ showed the best antimicrobial activity at highest concentration. This finding agrees with the results of Afzal A et al. ${ }^{8}$ Oliveira DP et al. ${ }^{9}$ Berber VB et al. ${ }^{10}$ The antimicrobial effect, tissue dissolution 
ability, and appropriate biologic compatibility in less concentrated solutions are all important characteristics of this irrigant.

Hypochlorous acid ( $\mathrm{HOCl}$ ) is formed when $\mathrm{NaOCl}$ is added to water. It contains active chlorine, which is a strong oxidizer. Chlorine acts as an antibacterial agent by irreversibly oxidising the -SH groups of essential enzymes, interrupting the bacterial cell's metabolic functions. It may also form $\mathrm{N}$-chloro compounds by combining with cytoplasmic components, which are toxic complexes that kill the microorganism. However, even before the formation of $\mathrm{N}$ chloro compounds in the cytoplasm, the first contact oxidation reactions of chlorine with bacteria can result in the rapid death of bacterial cells. ${ }^{11}$,

In higher concentration, it is considered to be more aggressive while in lower concentration $(0.5 \%-1 \%)$, it is biocompatible. Tissue dissolution property is concentration dependent. $5 \% \mathrm{NaOCl}$ dissolves pulpal tissue \& necrotic debris rapidly. However, higher concentration is cytotoxic. Volume of this cytotoxic solution can be reduced by using it with an adjuvant irrigating solution.

In the existent study, $0.5 \% \mathrm{NaOCl}$ exhibited little antimicrobial action. This could be due to precipitation of the solution on the paper disc, during saturation procedure. According to Ayhan $\mathrm{H}$ et al.11 Baumgartner \& Cuenin, ${ }^{12}$ Heling \& Chandler, ${ }^{13}$ microorganisms such as E. faecalis are resistant to $\mathrm{NaOCl}$, particularly at low concentration. Byström A, Sundqvist $\mathrm{G}^{14}$ showed that $\mathrm{NaOCl}$ was far less effective when diluted to a clinically significant level $(0.5 \%)$.

In the current study, $2.5 \% \mathrm{NaOCl}$ and $2 \% \mathrm{CHX}$ showed a better antimicrobial effect than OCT and Green tea. Kustarci A et al. also concluded that $2.5 \% \mathrm{NaOCl}$ and $2 \% \mathrm{CHX}$ have superior antimicrobial effect than OCT and propolis, against E. faecalis, C. albicans, $S$. aureus and E. coli. At low concentration of chlorhexidine, small molecular weight substance leaks out, leading to a bacteriostatic effect. At higher concentration, it has a bactericidal effect. It precipitates or coagulates the cytoplasm, most likely caused by protein. ${ }^{15,16}$ Antimicrobial activity is $\mathrm{pH}$ dependant, with the optimal range being $5.5-0.741 .{ }^{17}$

In the existent study, green tea showed antimicrobial activity against E. faecalis. Pujar $\mathrm{M}$ et al. ${ }^{18}$ also stated that green tea showed a better antimicrobial activity against $E$. faecalis. Martina LP et al. ${ }^{19}$ showed that $3 \%$ green tea extract has same antibacterial activity against $E$. faecalis as $2 \%$ CHX. Green tea contains catechin compounds like: Catechin, epicatechin, epigallocatechin, epicatechin gallate, and epicallocatechin gallate (also known as EGCG). It binds to the lipid bilayer and causes aggregation of lipid vesicles and leaks the contents from a suspension of vesicles. It causes membrane expansion leading to membrane thickening, loss of cell structure, and finally death. It also interferes with the DNA replication process by inhibiting bacterial DNA gyrate enzyme. EGCG is found to be the most active component in green tea.

In the present study, $5 \% \mathrm{NaOCl}$ is more effective than 0.1 $\%$ octenidine. Tirali RE et al. ${ }^{20}$ (2009) in their study showed that $100 \%$ and $50 \%$ octenidine hydrochloride are more effective than $5.25 \% \mathrm{NaOCl}$ against $S$. aureus, E. faecalis and Candida albicans. As a cation - active substance, octenidine binds readily to the negatively charged bacterial cell envelope, consequently disrupting the vital functions of the cell membrane, and killing the cell. It is relatively nontoxic. As compared to $\mathrm{NaOCl}$ and $\mathrm{CHX}^{5}$, it has a faster ability to produce intratubular disinfection and is effective against endodontic pathogens, making it a better alternative for root canal irrigation than CHX.20

Octenidine's antiadhesive property prevents biofilm formation better than chitosan and CHX. ${ }^{21}$ These properties, as well as OCT's ability to inactivate already formed biofilms even in the presence of serum proteins, ${ }^{22}$ is an advantage over $\mathrm{NaOCl}$, which is found to lose its efficacy in the presence of organic matter. ${ }^{23}$ Dentin, tissue debris, blood, and their mixtures will quickly reduce $\mathrm{NaOCl}$ 's antibacterial effectiveness. $\mathrm{NaOCl}$ alone cannot eradicate persistent mature biofilm communities within the root canal space. ${ }^{24}$

When OCT is mixed with $\mathrm{NaOCl}$, phenoxyethanol (PE), which is already present in commercial OCT solution, precipitates. PE is not toxic, ${ }^{25,26,27}$ at doses used in OCT.

$\mathrm{PE}$ is effective against oral bacteria and subgingival plaque, and evidence suggests that it works in conjunction with other antimicrobials. ${ }^{28,29}$ Potential of octenidine as an individual irrigant is inadequate due to its poor tissuedissolving properties. ${ }^{30}$ It has good in-vivo tissue tolerance and thus could be used in regenerative endodontics, especially in teeth with a large open apex. ${ }^{31}$ OCT can be used along with $\mathrm{NaOCl}$ to circumvent the problems associated with sodium hypochlorite.

\section{CONCLUSIONS}

Within the limitations of this study, it is concluded that $5 \%$ sodium hypochlorite has better antimicrobial property than other experimental irrigants. $2.5 \% \mathrm{NaOCl}$ and $2 \% \mathrm{CHX}$ showed a better antimicrobial effect than $0.1 \%$ OCT and $3 \%$ Green tea. Antibacterial and antifungal properties of $0.1 \%$ OCT is better than that of $3 \%$ Green tea. $0.1 \%$ OCT can be used as a contributory irrigant along with $\mathrm{NaOCl}$ to achieve antimicrobial advantage and reduce problems associated with usage of sodium hypochlorite, although this needs further clinical appraisal.

Data sharing statement provided by the authors is available with the full text of this article at jemds.com.

Financial or other competing interests: None.

Disclosure forms provided by the authors are available with the full text of this article at jemds.com.

\section{REFERENCES}

[1] Siqueira JF Jr, Sen BH. Fungi in endodontic infections. Oral Surg Oral Med Oral Pathol Oral Radiol Endod 2004;97(5):632-41.

[2] Tirali RE, Bodur H, Sipahi B, et al. Evaluation of the antimicrobial activities of chlorhexidine gluconate, sodium hypochlorite and octenidine hydrochloride in vitro. Aust Endod J 2013;39(1):15-8.

[3] Ganesh C, Koshy PA, Devi LS, et al. Comparative evaluation of the effect of proton pump inhibitors associated with calcium hydroxide on Enterococcus 
faecalis: an in vitro study. Endodontology 2016;28(1):710.

[4] Makkar S, Aggarwal A, Pasricha S, et al. Comparative evaluation of octenidine hydrochloride and chlorhexidine as antibacterial root canal irrigant. Indian J Oral Sci 2015;6(1):10-3.

[5] Tirali RE, Bodur H, Ece G. In vitro antimicrobial activity of sodium hypochlorite, chlorhexidine gluconate and octenidine dihydrochloride in elimination of microorganisms within dentinal tubules of primary and permanent teeth. Med Oral Patol Oral Cir Bucal 2012;17(3):e517-22.

[6] Kustarci A, Oktay EA, Kılıç A, et al. Evaluation of antimicrobial efficacy of sodium hypochlorite, propolis, octenidine dihydrochloride and chlorhexidine on microorganisms. Cumhuriyet Dent J 2011;14(3):183-90.

[7] Mujoo T, Balial V. Novel root canal irrigants: an endodontic experience. Int J Dent Health Sci 2014;1:35666.

[8] Afzal A, Gopal VR, Pillai R, et al. Antimicrobial activity of various irrigants against $\mathrm{E}$. faecalis biofilm: an in vitro study. J Interdiscip Dentistry 2013;3(2):103-8.

[9] Oliveira DP, Barbizam JVB, Trope M, et al. In vitro antibacterial efficacy of endodontic irrigants against Enterococcus faecalis. Oral Surg Oral Med Oral Pathol Oral Radiol Endod 2007;103(5):702-6.

[10] Berber VB, Gomes BPFA, Sena NT, et al. Efficacy of various concentrations of $\mathrm{NaOCl}$ and instrumentation techniques in reducing enterococcus faecalis within root canals and dentinal tubules. Int Endod J 2006;39(1):107.

[11] Ayhan H, Sultan N, Cirak M, et al. Antimicrobial effects of various endodontic irrigants on selected microorganisms. Int Endod J 1999;32(2):99-102.

[12] Baumgartner JC, Cuenin PR. Efficacy of several concentrations of sodium hypochlorite for root canal irrigation. J Endod 1992;18(12):605-12.

[13] Heling I, Chandler NP. Antimicrobial effect of irrigant combinations within dentinal tubules. Int Endod J 1998;31(1):8-14.

[14] Byström A, Sundqvist G. Bacteriologic evaluation of the effect of 0.5 percent sodium hypochlorite in endodontic therapy. Oral Surg Oral Med Oral Pathol 1983;55(5):30712.

[15] Gomes BPFA, Souza SFC, Ferraz CCR, et al. Effectiveness of $2 \%$ chlorhexidine gel and calcium hydroxide against Enterococcus faecalis in bovine root dentine in vitro. Int Endod J 2003;36(4):267-75.

[16] Greenstein G, Berman C, Jaffin R. Chlorhexidine. An adjunct to periodontal therapy. J Periodontol 1986;57(6):370-7.

[17] Kandaswamy D, Venkateshbabu N. Root canal irrigants. J Conserv Dent 2010;13(4):256-64.

[18] Pujar M, Patil C, Kadam A. Comparison of antimicrobial efficacy of Triphala, (GTP) Green tea polyphenols and 3
$\%$ of sodium hypochlorite on Enterococcus faecalis biofilms formed on tooth substrate: in vitro. J Int Oral Health 2011;3(2):23-9.

[19] Martina LP, Ebenezar AVR, Ghani MF, et al. An in vitro comparative antibacterial study of different concentrations of green tea extracts and $2 \%$ chlorhexidine on Enterococcus faecalis. Saudi Endod J 2013;3(3):120-4.

[20] Tirali RE, Turan Y, Akal N, et al. In vitro antimicrobial activity of several concentrations of $\mathrm{NaOCl}$ and Octenisept in elimination of endodontic pathogens. Oral Surg Oral Med Oral Pathol Oral Radiol Endod 2009;108(5):e117-20.

[21] Decker EM, Weiger R, Wiech I, et al. Comparison of antiadhesive and antibacterial effects of antiseptics on streptococcus sanguinis. Eur J Oral Sci 2003;111(2):1448.

[22] Amalaradjou MA, Venkitanarayanan K. Antibiofilm effect of octenidine hydrochloride on Staphylococcus aureus, MRSA and VRSA. Pathogens 2014;3(2):404-16.

[23] Haapasalo $M$, Shen $Y$, Qian $W$, et al. Irrigation in endodontics. Dent Clin North Am 2010;54(2):291-312.

[24] Yang Y, Shen Y, Wang Z, et al. Evaluation of the susceptibility of multispecies biofilms in dentinal tubules to disinfecting solutions. J Endod 2016;42(8):1246-50.

[25] Anselmi C, Ettorre A, Andreassi M, et al. In vitro induction of apoptosis vs.necrosis by widely used preservatives: 2-phenoxyethanol, a mixture of isothiazolinones, imidazolidinyl urea and 1,2-pentanediol. Biochem Pharmacol 2002;63(3):437-53.

[26] Scortichini BH, Quast JF, Rao KS. Teratologic evaluation of 2-phenoxyethanol in New Zealand white rabbits following dermal exposure. Fundam Appl Toxicol 1987;8(2):272-9.

[27] Troutman JA, Rick DL, Stuard SB, et al. Development of a physiologically-based pharmacokinetic model of 2phenoxyethanol and its metabolite phenoxyacetic acid in rats and humans to address toxicokinetic uncertainty in risk assessment. Regul Toxicol Pharmacol 2015;73(2):530-43.

[28] Wilson M, Stanley A, Bansal G, et al. Effect of phenoxyethanol, chlorhexidine and their combination on subgingival plaque bacteria. J Antimicrob Chemother 1990;25(6):921-9.

[29] Wilson M, Bansal G, Stanley A, et al. Susceptibility of oral bacteria to phenoxyethanol and phenoxyethanol/chlorhexidine combinations. J Periodontol 1990;61(8):536-41.

[30] Arslan D, Guneser MB, Kustarci A, et al. Pulp tissue dissolution capacity of QMix 2in1 irrigation solution. Eur J Dent 2015;9(3):423-7.

[31] Jenull S, Hojdar $\mathrm{K}$, Laggner $\mathrm{H}$, et al. Cell growth and migration under octenidine-antiseptic treatment. J Wound Care 2015;24(6):282-8. 